\title{
Performance Analysis of an Installed 1.5kva Hybrid Power Supply
}

\author{
${ }^{1}$ Ekpenyong, E.E, ${ }^{2}$ Bam, M.E and ${ }^{3}$ Anyasi, F.I \\ ${ }^{1,2}$ Department of Electrical/Electronic Engineering, Cross River University of Technology, P.M.B 1123, \\ Calabar. Nigeria. \\ ${ }^{3}$ Department of Electrical and Electronics Engineering, Ambrose Alli University, P.M.B 14, Ekpoma, Edo State, \\ Nigeria.
}

\begin{abstract}
This work models a 1.5KVA grid connected solar power supply system using a combination of $P V$ array, charge controller, inverter, battery bank, A.C load and installation accessories which work complementarily to capture the best feature of the energy resources and provide the grid-connected location with the highest electricity network quality and reliability. The system operate at minimum running cost, population free environment, noiseless, reliable and provide the convenient of a twenty-four hour power supply. With this system, energy efficiency is achieved by lowering demand using demand response, incorporating temporary and permanent load shifting by back-up and parallel mode respectively. The system was installed at the administrative office of the head of department, electrical and electronic engineering department in Cross River University of technology, Calabar, Nigeria. The total energy is obtained by direct inspection and energy audit. The optimization of the system is based on numerical and analytical modelling and HOMER software package. The sizing results suggest that HOMER software is a powerful, efficient and flexible tool that gives the optimum and cost effective system based on renewable source.
\end{abstract}

Keywords: Performance analysis, Hybrid power, derating factor, HOMER's software

\section{Introduction}

The increasing demand of energy, the continuous reduction of natural resources of fossil fuels and the growing concern regarding the environment pollution, determined the mankind to explore new production technologies of electrical power using non-polluting renewable sources, such as wind energy, solar energy, sea waves, biomass [1] as well as geothermal energy, bio-fuel, hydropower, tidal power etc. Electrical power supply from renewable sources is advantageous as the increasing Electrical demand is a scientific contribution to the peak demand on the grid. As individuals and companies generate their power through renewable energy, the stress on the grid is reduced. However, there is an ongoing interest in the possibility of making wider use of renewable energy, particularly in homes, offices and industries, for the purpose of lighting, heating and powering of appliances. In most rural and sub-urban regions in Nigeria, inhabitants do not have access to electricity supply. Where the Electrical energy is available, it is not reliable; hence inhabitants resort to other forms of energy such as wood, paraffin, and diesel a generators, which pollutes the environment and cause harm to man and plants [2].

Nigeria is endowed with abundant renewable energy resources, like biomass, wind, small and large scale hydro with potential for hydrogen fuel, geothermal and ocean energies. Except for the large scale hydropower generating station which serves as a major source of electricity, the current state of exploitation and utilization of renewable energy resources in the country is very low[3]. The main constraint in the rapid development and diffusion of technology for the exploitation and utilization of renewable energy resources in the country is the absence of appropriate policy, regulatory and institutional framework to stimulate demand and attract investors. The comparative low quality of the systems developed and the high initial upfront also constitute barriers to the development of these systems.

The transmission network (that is from national grid) is overloaded with a wheeling capacity less than 4000MW. It has a poor voltage profile in most parts of the network, inadequate dispatch and control infrastructure, radial and fragile grid network, frequent system collapse, exceedingly high transmission losses [4]. It is a known fact that, Electric power availability enhances economic development of any society, while non availability of power or power outage creates economic hardship. The power sector is unable to match supply with demand of electric power and access to Electricity is low as about $60 \%$ of the population (approximately 80 million people in Nigeria) are not served with Electricity [5]. Electric power sustains the society in almost all ramifications; it becomes necessary for the Nigerian Government to sustain Electric power availability to its citizenry [6]. Electricity has never been adequate to the Nigerian populace, for 115 years now, epileptic power supply and blackout is a regular phenomenon. 
Solar energy is the energy transmitted from the sun in the form of electromagnetic radiation, which requires no medium for transmission. Solar energy is the most promising of the renewable energy sources in Nigeria, in view of its apparent unlimited potential. The sun radiates its energy at the rate of about $3.8 \times 10^{23} \mathrm{KW}$ per second [7]. Most of this energy is transmitted as electromagnetic radiation which comes to about $1.5 \mathrm{KW} / \mathrm{M}^{2}$ at the boundary of the atmosphere.

This work becomes necessary to demonstrate a Grid-connected solar power system for autonomous generation of electric power showing its efficiency, low running cost, reliability, silent operation, pollution free, minimal maintenance cost, automatic change-over system and an efficient payback system from the inexhaustible and free supply of the sun. The optimization of the system is based on numerical analytical modelling and the HOMER software package.

Typically, the solar modules are mounted on the roof of a building but our decision for mounting this project's solar module on a stand-alone rack is to give room for further expansion as well as the renovation of the workshop without the interruption of proper functioning of the system. A very important consideration is how much sun the panel gets in the location chosen.

\section{Materials And Method}

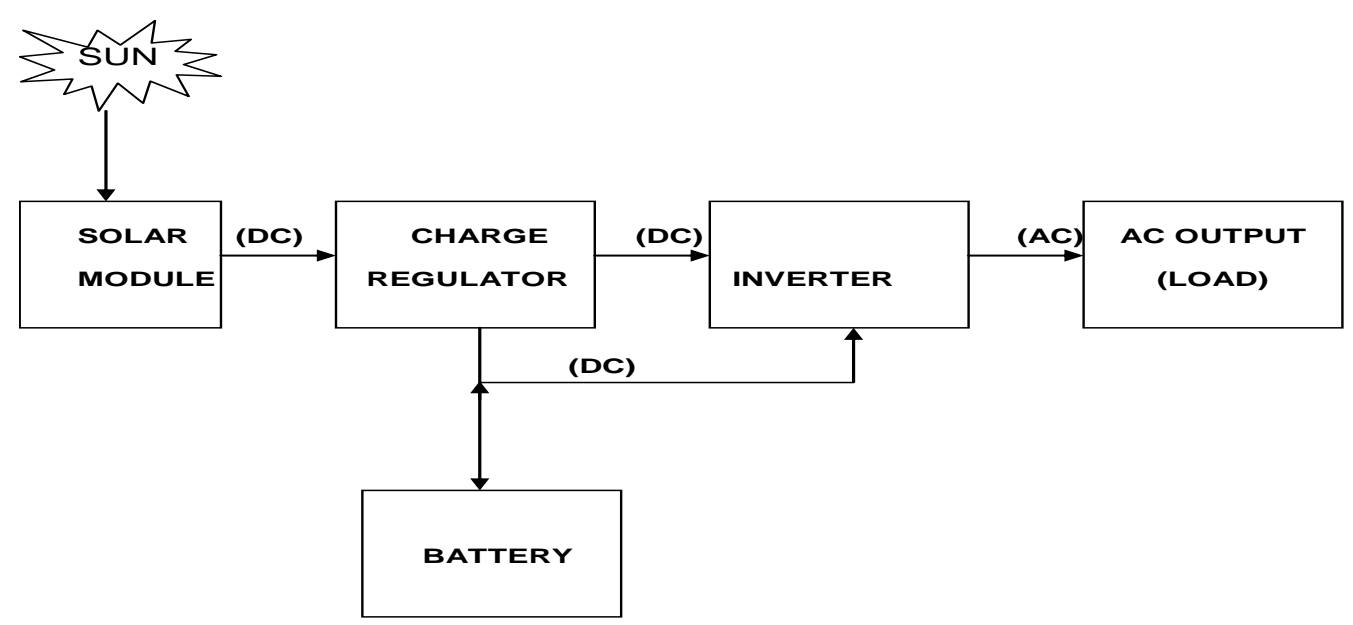

Figure 1: block diagram of the solar energy system

PV Installation: PV arrays for PV system are installed in many unique and innovative ways. However, there are common issues involved in any installation, whether the array is fixed or tracking, mounted at ground level or on a pole or on the roof of a building [8]. PV arrays are mounted at a fixed angle of 45 degrees facing east or on a tracking device that follows the sun, allowing them to capture the most of the day. The objective is to solidly mount PV array that will last for many years and withstand all kinds of weather. Customized array mounting structures are excluded in this project because of cost [9].

In general, roof mounting of PV modules is more complex than pole mounting. Roof mounts are more difficult to maintain, particularly if the roof orientation and angle are not compatible with the optimum solar tilt angle. If a roof mount is required, it is good practice to allow a clear space between roof and the array. The array will operate cooler and produce more energy if it stands off the roof at least 3 inches [9]. Flushing mounting PV modules to the roof of a building is not recommended as the modules become more difficult to test and replace, and the performance of the array is decreased because of the higher operating temperatures.

System Wiring: Wiring is used to distribute power to various devices selecting the correct size and type of wire enhances performance and reliability of solar PV system. The size of wire must be large enough to carry the maximum current without causing any voltage losses. When wiring up your solar energy system, make sure all wires are properly marked. This small effort during the installation process will significantly ease trouble shooting later: it enables you to identify wires at a glance without having to open cable trunks/dig up wires to see which one is leading where, or having to do complicated tests with a multi-meter. More importantly, it prevents cables from being displaced - which may be dangerous and damaging to your equipment [9].

Installation Configuration: The installation in this work is based on hybrid on-grid systems. The system essentially uses the existing commercial utility system for power and store electricity power in a battery. A solar PV system is installed into electrical system of the office facility for use during the day or day light hour and 
work when grid power is down. It also work the other way, when the solar PV does not produce enough electricity, it can draw power from the grid. If more electricity is produced than what is needed, the excess can be put back on the grid this is done automatically through a device that monitors the available power and switches between PV and grid power. A second utility meter can be added to keep track of how electricity has been put back on the grid action fee, the liability of solar component in the initial cost of the solar PV system [10].

A combination of an on grid and up grid solar PV system has the advantages of both a hybrid system is connected to the grid in case of poor weather or night use, but also has a battery bank to store electricity in case utility grid power is lost. The design and installation of hybrid system is more complicated and expensive, but they are the most effective in providing constant, reliable electricity [10].

Energy analysis: The equipments considered are photovoltaic solar modules, inverter, battery bank and loading system. The energy analysis carried out using HOMER software is shown in Figure 2.

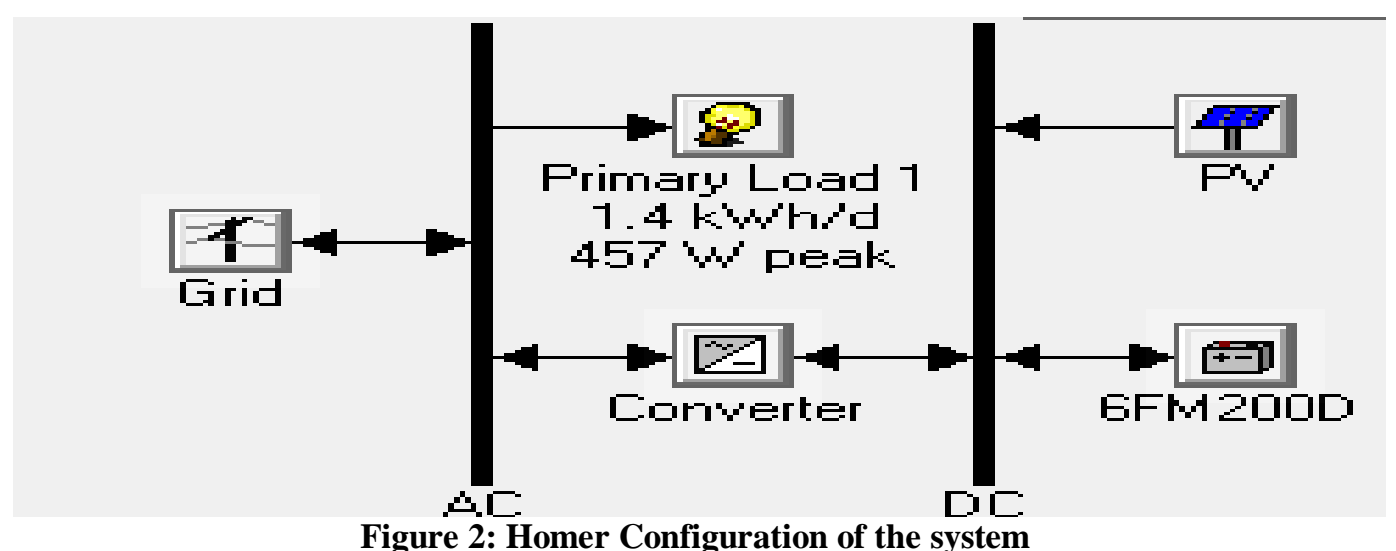

Expected Configuration of the system: The maximum power delivered by the hybrid power system is $1.5 \mathrm{KW}$, thus the DC/AC inverter has a rated power of $1.5 \mathrm{KW}$ to cover the power peaks;

- The DC bus is set to $24 \mathrm{~V}$

- The average monthly electric energy consumption of the system is $36 \mathrm{KWh} / \mathrm{month}$ with a maximum delivered electric power to the system of $456 \mathrm{~W}$ as shown in Fig 1.

- The $15 \mathrm{PV}$ panels of $110 \mathrm{Wp}$ per unit with output voltage of $24 \mathrm{~V}$ d.c to account for PV efficiency.

- The batteries are of vision 6FM 200D type, characterized by $12 \mathrm{~V}$ d.c. and $200 \mathrm{Ah}$; their number is multiple of 2 because the d.c bus bar voltage is $24 \mathrm{~V}$ d.c.

Daily load profile: The load profile is based on the H.O.D's office as shown in Fig 3, Peak loads of 240W run on the system throughout six (6) hours of the working days. The total daily load average 1440watt-hours per day. The seasonal load profile is shown in Figure 4.

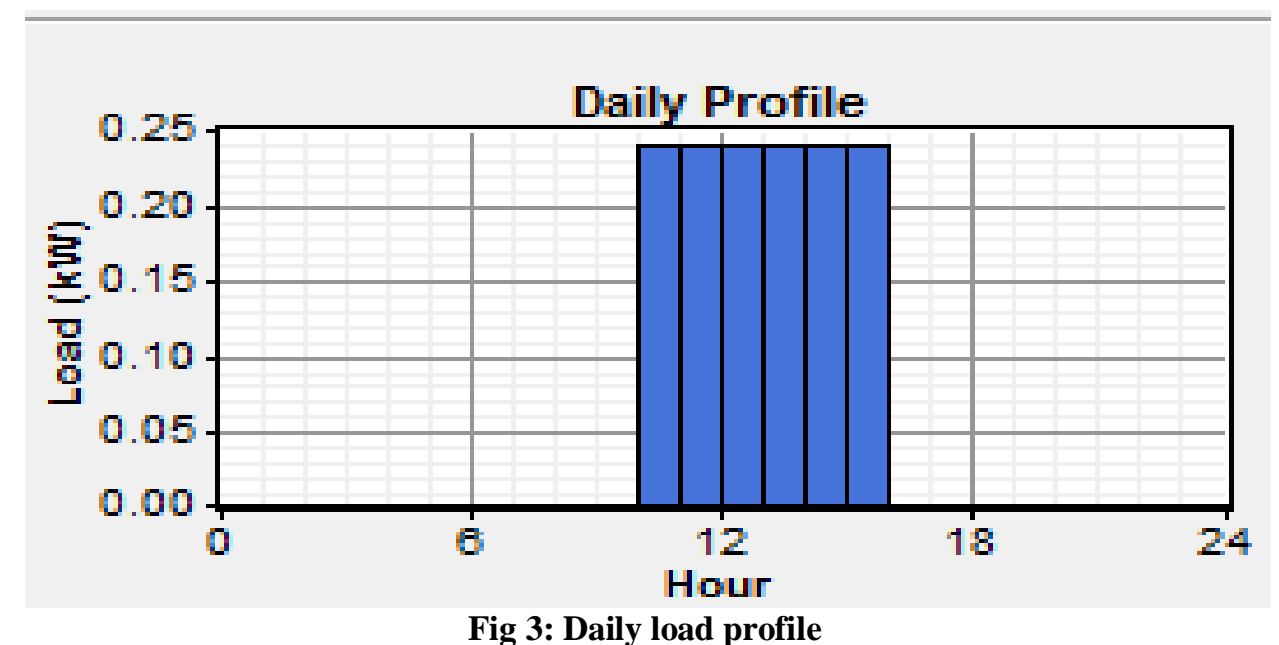

Fig 3: Daily load profile 


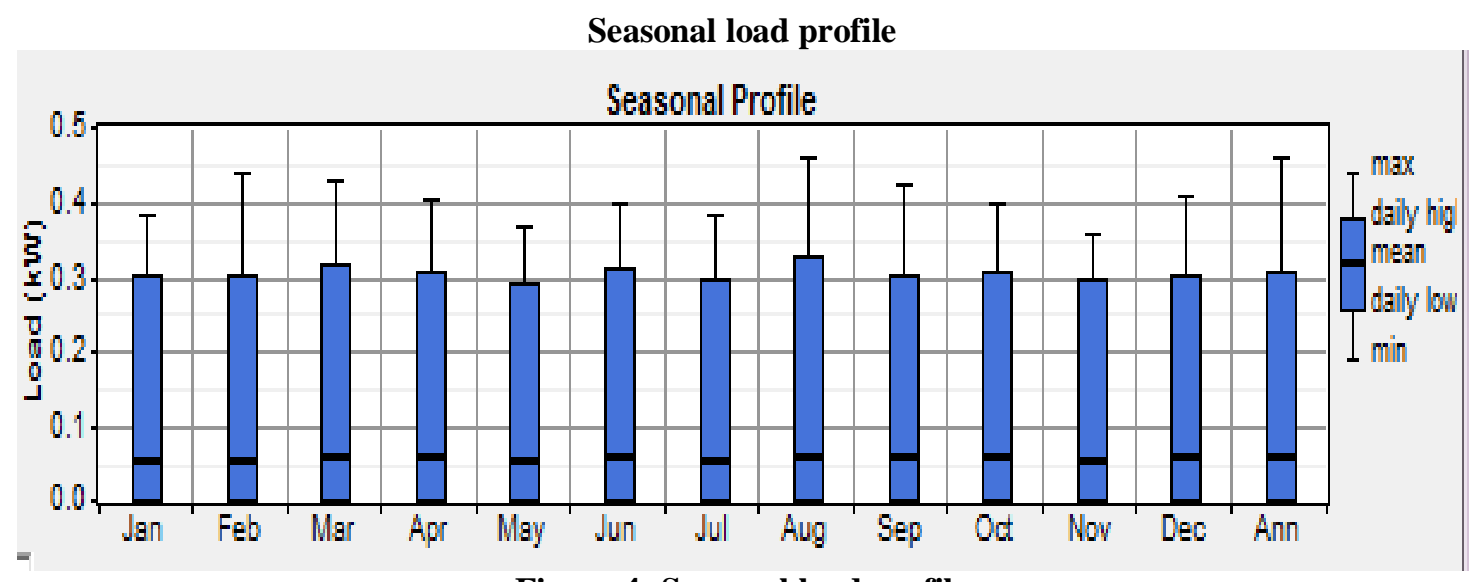

Figure 4: Seasonal load profile

Maximum power possible: The maximum power output of the installed PV is $0.2 \mathrm{kw}$ and is not adequate to charge the battery let alone power the $1.4 \mathrm{KW}$ load. This accounts for the blackout in the PV area. HOMER discards systems that do not satisfy the specific constraints so that they do not appear in the optimization or sensitivity results. However, the required PV size adequate for the installation is $1.65 \mathrm{KW}$ (13 more PV modules of $110 \mathrm{~W}$ each is required to make up for this shortfall). Figure 5 shows the contribution of the PV in the installed system.

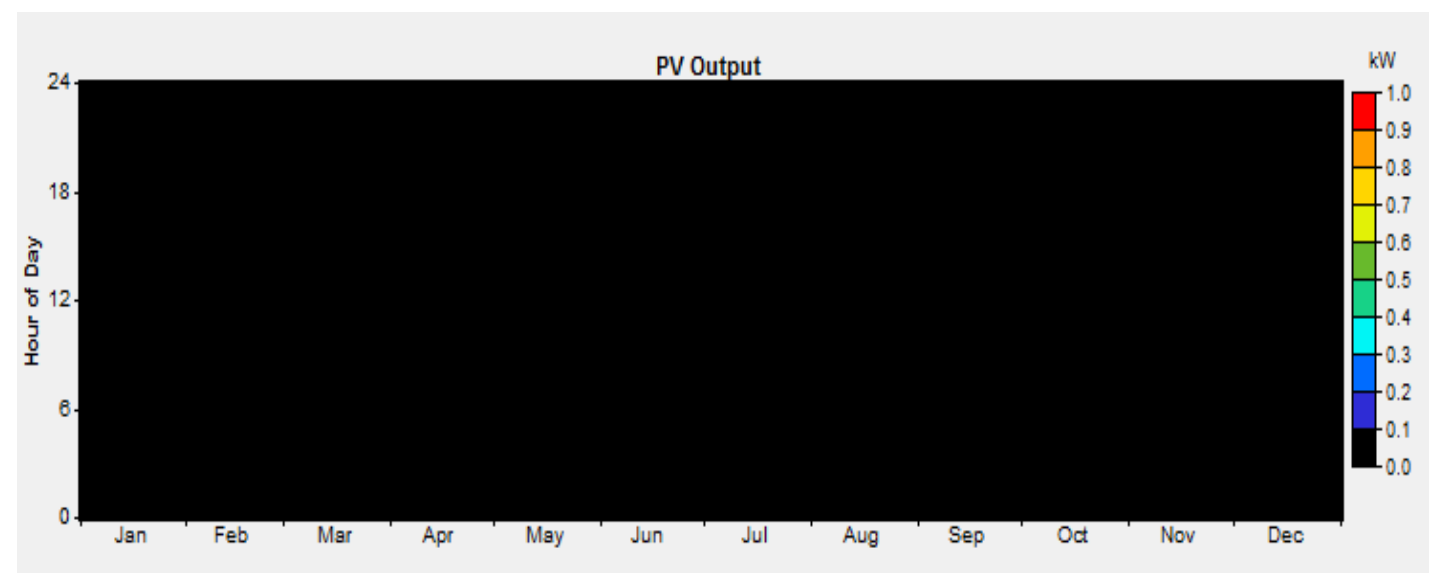

Figure 5: PV Output

\section{Data Map (D-Map)}

Data map (D-map) is a type of graph showing one year of time series data. With time of day on one axis and day of the year on the other, each time steps of the year is represented by a rectangle which is coloured according to the data value for that hour. The Dmap format often allows you to see daily and seasonal patterns more easily than you could with a simple time series plot. The D-map for the system is shown in Figure 6.

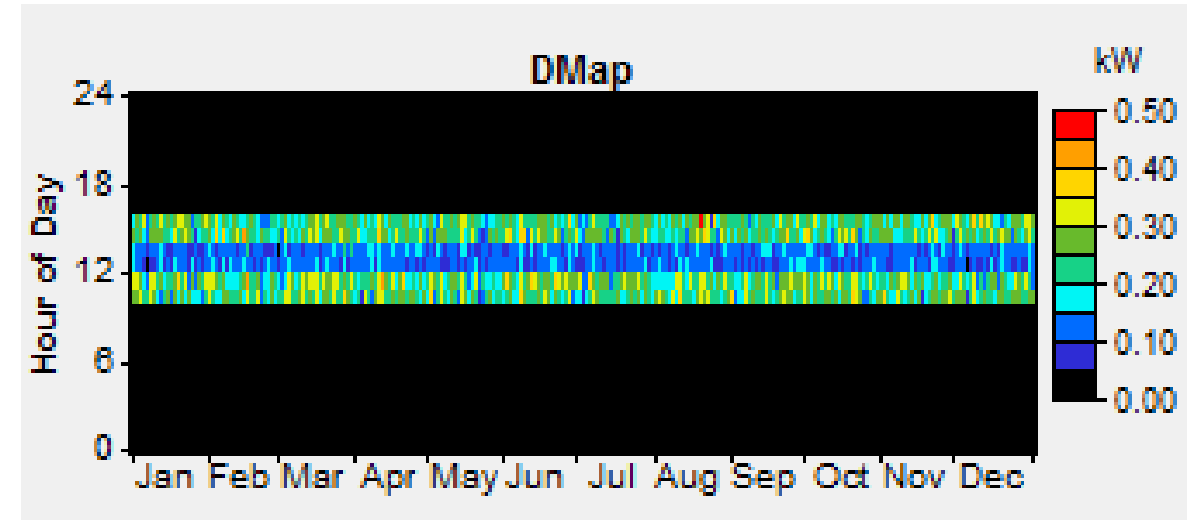

Figure 6: Data Map (D-Map) 
Solar Radiation Profile: Solar radiation and clearness index data is shown in Figure 7 (a).

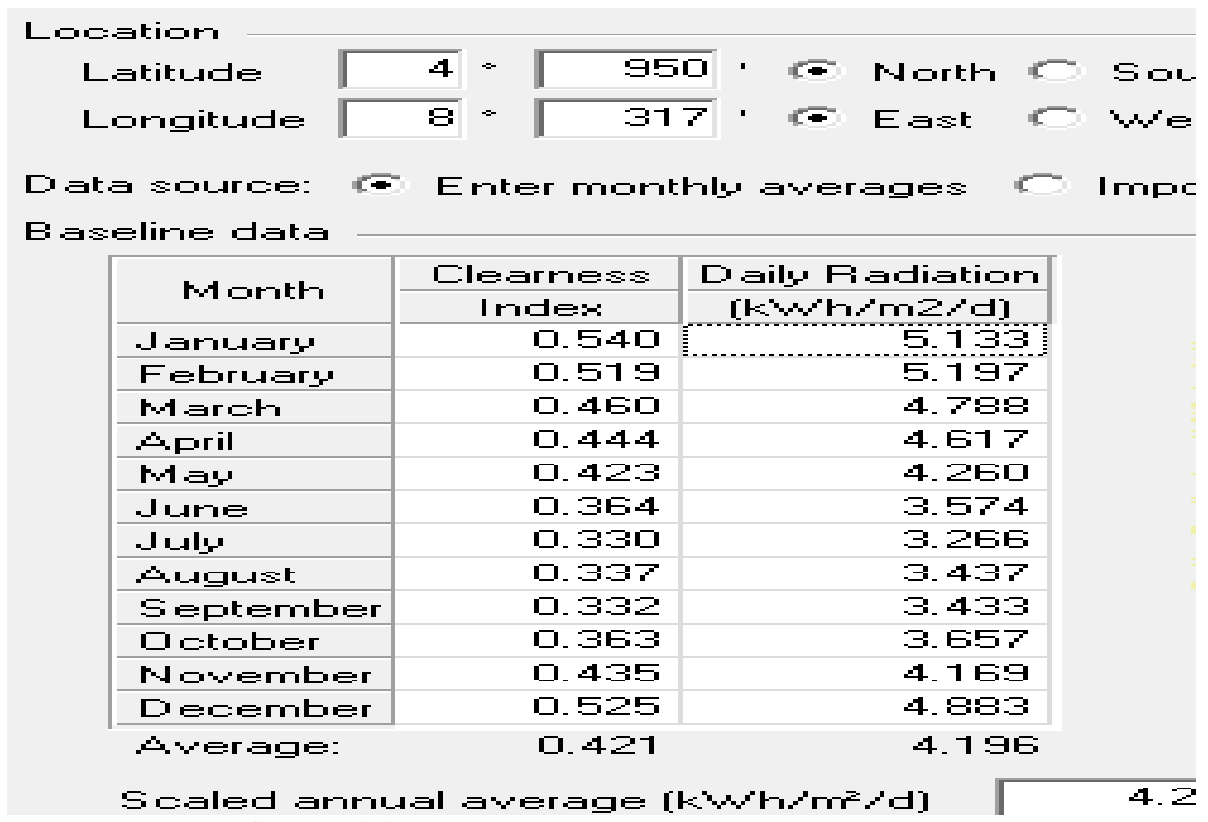

Figure 7(a): Solar radiation and clearness index data

Figure 7 (b) shows the solar resource profile over one year. The approximate location of the site used is $4{ }^{0} 950{ }^{1} \mathrm{~N}$ and $8{ }^{0} 29^{1} \mathrm{E}$. The solar resource data for Calabar, Nigeria was obtained from International Journal of Physical Sciences Vol. 4 (4), pp. 182-188, April, 2009 online at http://www.academicjournals.org/IJPS [11]. The solar radiation in Calabar is highest in the months of January, February, November and December. At these periods the PV output is highest as shown in the solar radiation graph in Figure 7(b).

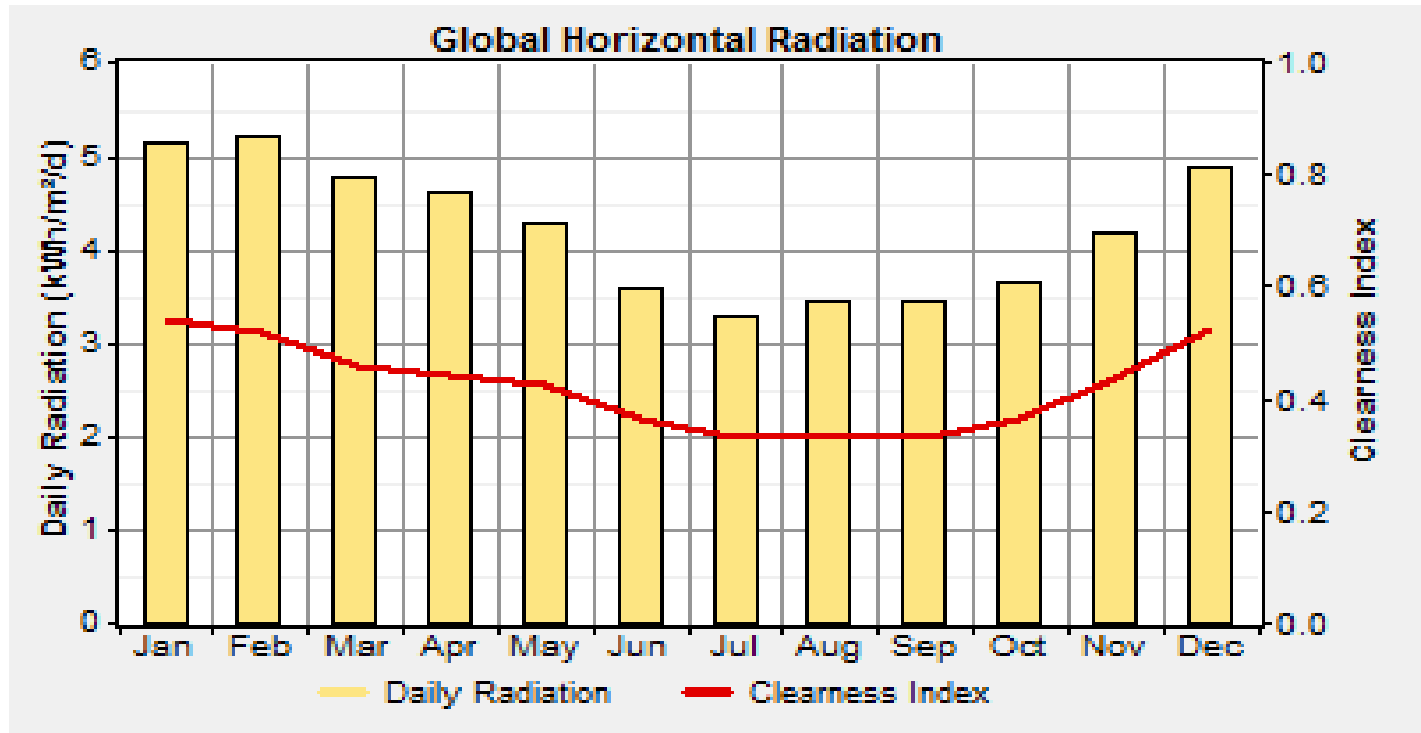

Fig 7 (b): Global Horizontal solar radiation graph

Economic Analysis: All costs associated with the Photovoltaic solar cells, including modules, mounting hardware and installation.

\section{Capital And Replacement Cost Curve Of PV System}

The capital and replacement costs were specified at $\$ 1000$ and $\$ 800$ respectively. A low maintenance cost was considered for the PV system because little or nomaintenance is needed for the panels and a derating factor of $80 \%$ and 20 years lifetime as shown in Figure 8. 


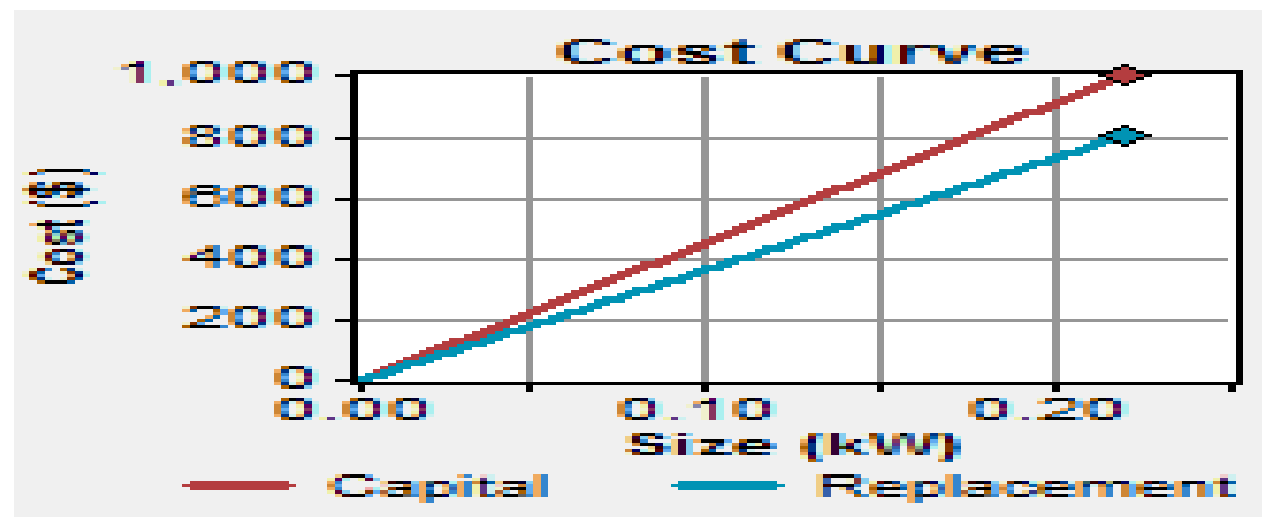

Figure 8: Capital and Replacement Cost Curve

The work life year was taken as 20 years. All calculations are done with exchange rate of N160. The tariff of the utility company in Nigeria, the power holding company of Nigeria (PHCN), is N130 per Kwh (\$0.813).

Cost of Charge controller: HOMER does not model the battery charge controller as a separate component. So, its cost and efficiency is usually included in the values specified for other components. For grid-connected PV system simulations, the best place to include the charge controller costs and efficiency is the PV array inputs. Then the PV derating factor is reduced to account for the efficiency of the charge controller. Hence, the derating factor of $80 \%$.

Battery bank cost profile: The battery bank cost profile is shown in Figure 9.

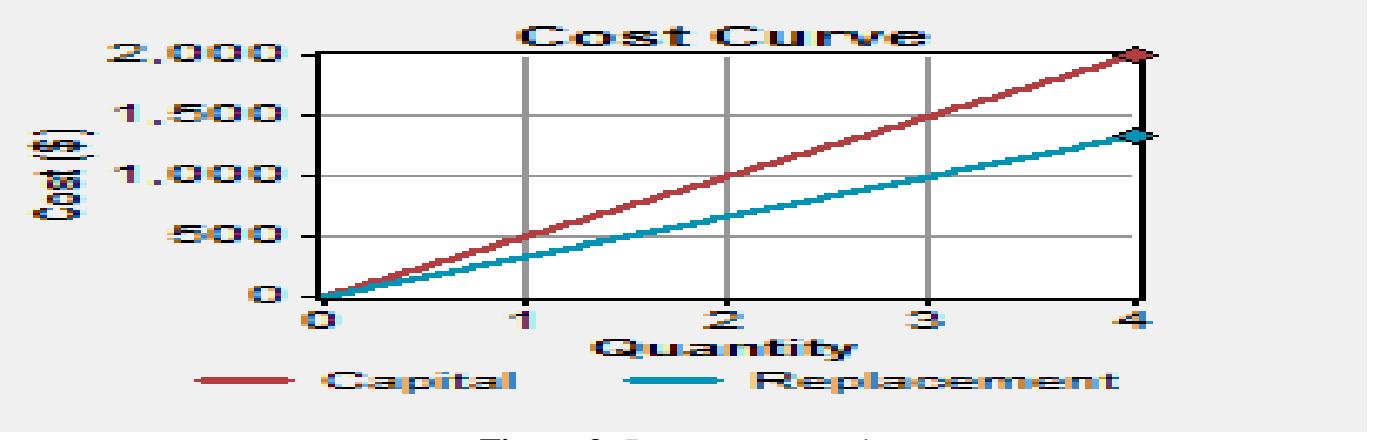

Figure 9: Battery cost graph

The capital and replacement costs were specified at $\$ 500$ and $\$ 333$ per battery respectively. Capital cost value of the battery include all costs associated with the battery bank, such as mounting hardware installation, labour and cost of a rack, room or building that houses the battery. The battery chosen is the 6FM200D series. It has a nominal voltage of 12 volts and nominal capacity of $200 \mathrm{Ah} / 2.4 \mathrm{kwh}$ with 4 years lifetime. Two batteries were considered by HOMER in the simulation as shown in Figure 9.

Inverter cost profile: The inverter costs include all the costs associated with the inverter, such as hardware and labour. The factors that gave rise to the curve as shown in Figure 10 are, inverter size, capital cost, replacement cost operation and maintenance cost, lifetime of 15years and inverter efficiency of $90 \%$.

Figure 10: Inverter cost graph

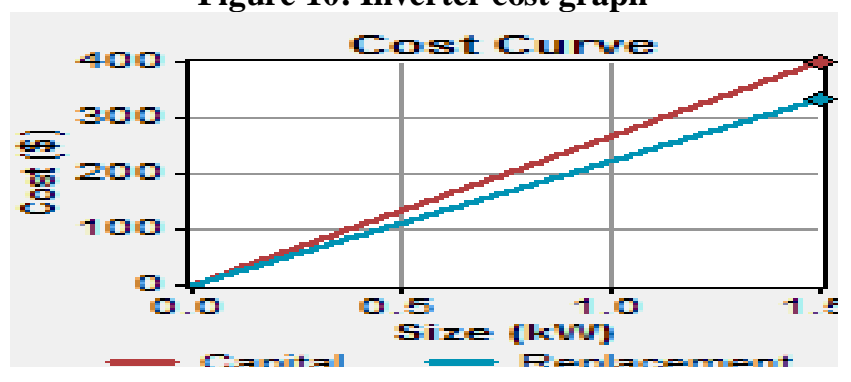


Cost summary: Table 1 shows the cost summary

Table 1: shows the cost summary

\begin{tabular}{|l|l|l|l|l|l|}
\hline Components & Size & $\begin{array}{l}\text { Capital } \\
\text { costs }(\$)\end{array}$ & $\begin{array}{l}\text { Replacement } \\
\text { cost }(\$)\end{array}$ & $\begin{array}{l}\text { O\&M cost } \\
(\$)\end{array}$ & Lifetime \\
\hline PV panels & $0.220(\mathrm{KW})$ & 1000 & 800 & $0.50 /$ year & 20years \\
\hline Battery & $\begin{array}{l}\text { 200Ah/12V } \\
\text { (bank size: } \\
\text { batteries) }\end{array}$ & $333 /$ battery & $333 /$ battery & $2.00 /$ year & $\begin{array}{l}\text { 4years or } \\
1000 \mathrm{kwh} \text { of } \\
\text { throughput } \\
\text { per battery }\end{array}$ \\
\hline Inverter & $1.5 \mathrm{KVA}$ & 400 & 333 & $1.00 /$ year & 15 years \\
\hline
\end{tabular}

\section{Sensitivity and Optimization simulation result}

HOMER's main economic output is the net present cost. All systems are ranked according to net present cost, and all other economic outputs are calculated for the purpose of finding the net present cost. The result obtained from the optimization gives the initial capital cost as $\$ 5,833$ and operating cost as $\$ 260 /$ year, total present cost (NPC) is $\$ 9,160$ and cost of energy (COE) is $\$ 1,363 / \mathrm{kwh}$. The payback period of the system is $25 y e a r s$ and not 20years as specified as the manufacturers. See Figure 11.

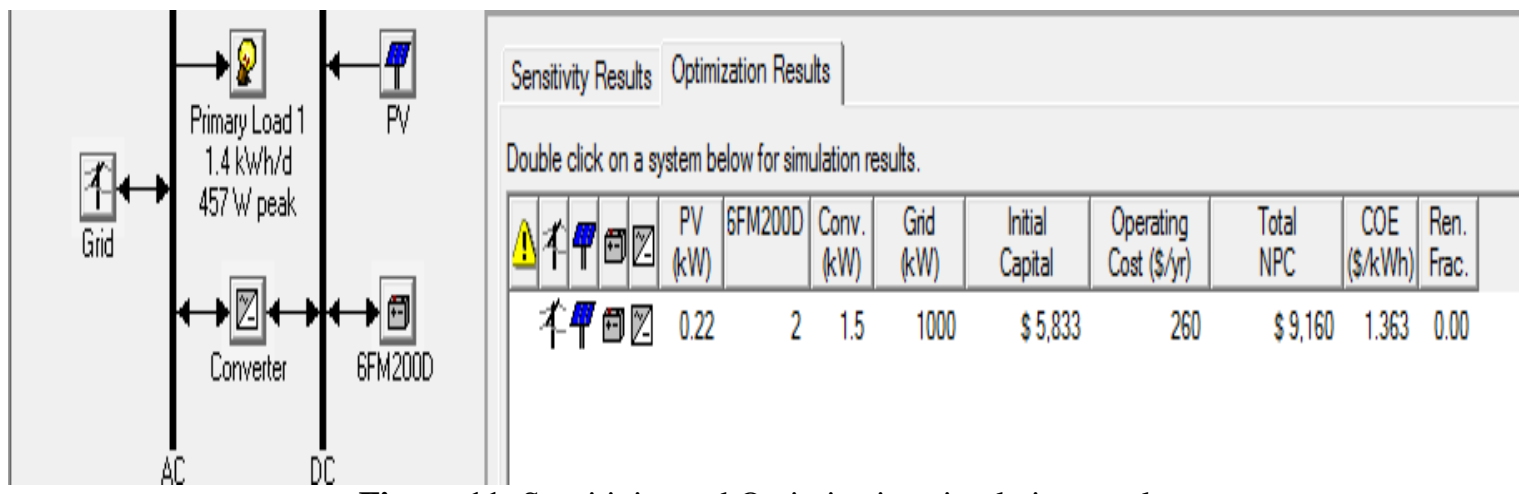

Figure 11: Sensitivity and Optimization simulation result

Load levels: The loads considered are typical domestic loads and include 5 fluorescent points, 2 ceiling fans, 5 laptops, two 14" television and 1 satellite decoder. The load input table is as shown Table 2.

Table 2:load input table (Baseline Data)

Month: January

Day Type: Weekday

\begin{tabular}{|l|l|}
\hline HOUR & LOAD $(\mathrm{KW})$ \\
\hline $10: 00-11: 00$ & 0.240 \\
\hline $11: 00-12: 00$ & 0.240 \\
\hline $12: 00-13: 00$ & 0.240 \\
\hline $13: 00-14: 00$ & 0.240 \\
\hline $14: 00-15: 00$ & 0.240 \\
\hline $15: 00-16: 00$ & 0.240 \\
\hline
\end{tabular}

Consequently the average load per day is $1.44 \mathrm{kwh} / \mathrm{d}$, average load per hour is $0.06 \mathrm{kw} / \mathrm{h}$, and peak load is $0.457 \mathrm{kw}$ and load factor of 0.131 all shown in Table 3 .

Table 3: load table

\begin{tabular}{|l|l|l|}
\hline & BASELINE & SCALE \\
\hline AVERAGE (Kwh/D) & 1.44 & 1.44 \\
\hline Average $(\mathrm{Kw})$ & 0.0600 & 0.0600 \\
\hline Peak $(\mathrm{Kw})$ & 0.457 & 0.457 \\
\hline Load Factor & 0.131 & 0.131 \\
\hline
\end{tabular}




\section{Payback period}

Research has shown that the lifespan of a PV system is between 20 and 25 years. Benefits abound in the choice of solar PV for self generation of electric power. Environmentally, solar power does not contribute to greenhouse gas emission. The payback period of solar power is estimated using the simple payback method as follows;

Payback period $=$ purchase and installation cost $/$ Expected annual savings.

For this project, the purchase and installation cost for the 1.5KVA PV stood at $\$ 9,160$ and cost of energy from utility supply per annum $\$ 1,363$.

Therefore, Payback period $=\$ 9,160 / \$ 1,363$

$=6.72$ years

$=7$ years.

The payback period is estimated at about 7 years. From this fact, the cost of the PV project will be paid off within 7 years while the remaining years is on profit making.

\section{Conclusion}

The installation in this work at Latitude $4^{0} 950^{\prime \prime}$ North and longitude $8^{0} 317^{\prime \prime}$ East is based on hybrid on-grid system. The system essentially uses the existing commercial utility and solar PV system for power and store electricity power in a battery. The system is installed into the electrical system of the office facility for use during the day or day light hour and when grid power is down. It can also work the other way, when the solar PV does not produce enough electricity, it can draw power from the grid. This is done automatically through a device that monitors the available power and switches between PV and grid power. The installation of hybrid system is more complicated and expensive, but they are the most effective in providing constant and reliable electricity. The grid tie inverter feed energy back into the distribution network because it produce alternating current with the same wave shape and frequency as supplied by the distribution system and can also turn on the hybrid system automatically in the case of power failure. The payback period is estimated at about 7 years. From this fact, the cost of PV work will be paid off within 7 years while the remaining years is on profit making. For the system to run as stand alone, the existing system should be upgraded by adding 13 more of same size of PV module and two additional 200Ah deep cycle batteries. A second utility meter can be added to keep track of how much electricity has been put back on the grid. Sun tracking parabolic trough and concentrating collectors could be added to improve the solar irradiation on the system. Provision could be made for the PV arrays to be mounted at a fixed angle of 45 degrees facing east or on a tracking device that follows the sun, allowing them to capture the most of the day. The aim of this work was to demonstrate that Hybridization of various renewable energy sources and battery bank is a key for system cost effectiveness and high performance than any other variant based on a single renewable source. The sizing results suggests that HOMER software is a powerful, efficient and flexible tool that gives the optimum and cost effective systems based on renewable source.

\section{References}

[1] Tiberiu T. \&Alexandru, M., “Optimum Design of wind/PV/Diesel/Batteries Hybrid systems.” 2008.

[2] M. Marvwan\& H. ImadIbrik, "Techno- economic feasibility of energy supply of remotevillages as Palestine by PV-systems, diesel generators and electric grid," renewable and sustainable energy. Reviews pp 128-138, 2006

[3] Sambo, A.S., International centre of energy, "Energy and Development Report, Renewable Electricity Action Program," federal ministry of power and steel, Nigeria 2006.

[4] Akpama, E.J.,'Designing a photovoltaic sustained sector: a review of current practice,'domestic use of energy conference, pp 155160. 2011.

[5] Chimeka I. U, \&chineke T. C. "Evaluating The Global Solar Energy Potential AtUturu, Nigeria.”International journal of physical sciences.Vol.4(3), pp 115-119, 2011.

[6] Dusabe, J.L. Munda, \&Jimoh A.A. "Small Scale Solar Energy System In Rwanda: Status. And Sustainability.”Domestic use of energy conference, pp 137-141, 2009.

[7] Rogers A. Messenger, " photovoltaic" floridaatlantic university, 2006

[8] G.D. Rai, "non-conventional energy sources.”Khanna publishers 2-B,Nath market, NaiSarak Delhi-m110006. India.2008

[9] Retrieved from " http://en.wikipedia.org/wiki/portal:Renewableenergy."

[10] Donald E.O. \& David E.C., "Utility Grid-Connected Distributed Power Systems.” National solar energy conference.ASES solar, 1996.

[11] Augustine C. \&Nnabuchi M. N. "Relationship between Global Radiation And. Sunshine Hours ForCalabar, Port Harcourt And Enugu, Nigeria.” International Journal of physical sciences vol. 4(4), pp.182-188, 2009. 